\section{Effect of Endodontic Sealer in Young Molars Treated by Undergraduate Students - A Randomized Clinical Trial}

Suely Aparecida Cunha ${ }^{1} \mathbb{B}$, Carlos José Soares ${ }^{1}$, Camila Maria Peres Rosatto $^{2} \mathbb{B}$, João Victor Soares Mendonça Vieira ${ }^{2}$, Renata Afonso da Silva Pereira ${ }^{1}$, Priscilla Barbosa Ferreira Soares ${ }^{3}{ }^{\circ}$, Cláudio Rodrigues Leles $^{4}$, Camilla Christian Gomes Moura²

\begin{abstract}
The progression of caries in permanent molar teeth of young patients, frequently result in endodontic treatment. This randomized blinded clinical trial assessed the effect of two endodontic sealers (Sealer 26 and AH Plus) on the incidence of pain and apical repair after endodontic treatment of young molar teeth, and secondly identify factors associated with the outcomes. Endodontic treatment was performed by undergraduate students in molar teeth $(n=69)$ of young patients $(n=54)$ at the Endodontic and Restorative Public Extension Clinic Service. Protaper Next was used and the endodontic sealers were allocated which were restored with direct composite resin. Two primary clinical outcomes - apical repair and postoperative pain, were assessed after 12 and 24 months for blinded operators. Description of incidence rates and mixed-model regression using Generalized Estimation Equations (GEE). After 2 years 69 molar teeth of 54 patients were evaluated. No effect of the endodontic sealer was observed irrespective of period of evaluation. Apical repair incidences and asymptomatic teeth were, respectively, 90.5 and 89.3, 96.8 and 90.0\% during 1 and 2 years of follow-up. Failed apical repair was associated with unsatisfactory pulpectomy $(p=0.003)$ and periapical conditions $(p=0.007)$ as well as their interaction $(p=0.016)$. None of these independent variables was able to predict the occurrence of pain in both periods. Prognosis of apical repair is dependent on the initial conditions. Endodontic treatment of young molars associated with composite resin restorations performed by undergraduate students have satisfactory results after 2 years and was effective to prevent the risk of permanent teeth loss.
\end{abstract}

'Biomechanics Research Group, Department of Operative Dentistry and Dental Materials, School of Dentistry, UFU - Universidade Federal de Uberlândia, Uberlândia, MG, Brazil ${ }^{2}$ Department of Endodontics, School of Dentistry, UFU Universidade Federal de Uberlândia, Uberlândia, MG, Brazil

${ }^{3}$ Department of Periodontology and Implantology, School of Dentistry, UFU - Universidade Federal de Uberlândia, Uberlândia, MG, Brazil. ${ }^{4}$ Department of Prevention and Oral Rehabilitation, School of Dentistry, UFG - Universidade Federal de Goiás, Goiânia, GO, Brazil

Correspondence: Profa. Camilla Christian Gomes Moura, Avenida Pará, 1720, Bloco 4L, Anexo A, sala 24, 38400-902, Uberlândia-MG/ Brasil. Tel: +55-34-3225-8103. E-mail: camillamoura@ufu.br

Key Words: pain, periapical tissue, young molar teeth, root canal therapy.

\section{Introduction}

Molars are the first permanent teeth to erupt, which occurs between 5 and 7 years of age, when the mixed dentition is established (1). The difficulty of proper hygiene due to the early age of patients associated with parent's failure to notice the eruption of the posterior permanent teeth may contribute to caries progression (2). In addition, despite the reduction in caries incidence rates in development countries, it is still a public health problem associated with lower socioeconomical status which mainly affects children and adolescents $(2,3)$. Caries progression in young molar teeth frequently results in endodontic treatment need to avoid tooth extraction (4). However, children and adolescents whose permanent molar teeth require root canal treatment $(\mathrm{RCT})$ are sometimes neglected in public health services, leading to early tooth loss, and consequent changes in occlusion, chewing function and psychosocial impairment (4).

Endodontic treatment of molar teeth is not universally included in undergraduate curriculum, and dentists in public services often do not have proper training for more complex endodontic procedures. The higher complexity involved in this clinical procedure in young molars is related to the larger pulp chamber, greater porosity in the furcation region, wider root canals with open apex, and sometimes the teeth are partially unerupted and severely compromised due to extensive caries lesion, which difficult the proper use of rubber dam isolation (5). The use of rotary instrumentation in undergraduate teaching accelerates the learning curve and improves the technical quality of endodontic treatment in multirooted teeth (6-8). However, the use of the rotary instrumentation technique in permanent molars of young patients is not supported in the literature by means of clinical studies, being performed based on the operator's previous experience.

Root canal filling in molar teeth also represents one of the greatest challenges for undergraduate students (6), resulting in higher rates of endodontic mishaps, loss of working length (WL), obturation beyond $2 \mathrm{~mm}$ from the radiographic apex, and overfill with gutta-percha (7). Ideally the filling material should be restricted to the intraradicular space $(9,10)$. The presence of extruded material may retard the healing process, especially in apical periodontitis (10). The consequences of extruded filling material are related 
to the biocompatibility of the material, the solubility in periapical tissues and the susceptibility to phagocytosis (9). Although previous studies have evaluated the effects of different sealers on the outcome of endodontic treatment (9-11), on the best of author's knowledge to date there are no clinical studies that have evaluated the influence of a set of pulpal, periapical and periodontal features on the outcomes of endodontic treatment in young molars filled with resinous endodontic sealers performed by undergraduate students.

Therefore, the aim of this study was to compare the clinical and radiographic effect of two endodontic sealers Sealer 26 and AH Plus on the incidence of pain and apical repair after endodontic treatment of young molar teeth, and secondly identify factors associated with treatment outcomes of endodontic treatment of young molars performed by undergraduate students over a 2-year follow up.

\section{Material and Methods}

This prospective, two-warms, blind, single-center, randomized, clinical trial performed by undergraduate students was approved by the Research Ethics Committee $\vec{s}$ of Federal University of Uberlândia, MG, Brazil (protocol 1.331.990) the parents of the patients signed a consent form for the adolescents to participate after being informed of the aims of the study. This study followed Consolidated Standards of Reporting Trials (CONSORT) guidelines with an extension for within-person designs (12). Longitudinal assessment was performed immediately after endodontic procedure and after 1 and 2 years. Sample size calculation was based on data from a previous study (13), and a minimum of 34 teeth for each group was defined, considering a 0.80 power, 0.25 effect size, and 0.05 significance level. Fifty-four participants, mean age 14 years old (range $=9-17$ years) referred to the Endodontic and Restorative Service for Adolescents from March 2015 to March 2016. All clinical procedures were performed by undergraduate students assisted by a clinical tutor (8).

\section{Eligibility Criteria}

Included participants were healthy children and adolescent aged between 9 and 17 years, with extensive coronary destruction by caries compromising more than $1 / 3$ of the coronal structure, and first or second molar teeth diagnosed with symptomatic irreversible pulpitis or necrosis, associated or not with apical periodontitis. Exclusion criteria comprised selected teeth with severe periodontal disease, root resorption or previous RCT, as well as the presence of systemic diseases such as uncontrolled diabetes, acquired immunodeficiency syndrome or other immunocompromised condition, pregnancy, or allergy to local anesthetics.

\section{Pulpal Diagnosis and Periapical Status}

After anamnesis and digital periapical radiographic examination, pulp diagnosis was tested using a cold spray test (Endo-Frost, Coltene Whaledent, Langenau, Germany). The cold spray was applied on the occlusal and buccal surfaces of the molar for $5 \mathrm{~s}$ with the aid of a cotton swab, and compared with an adjacent tooth with vital pulp without caries. Diagnosis of symptomatic irreversible pulpitis was made based on clinical findings, as spontaneous pain and prolonged response with moderate to severe pain to the cold stimulus. Pulp vitality was confirmed visually by the presence of bleeding when entering the pulp chamber during endodontic access. The clinical diagnosis of pulp necrosis was confirmed by absence of response to the cold test, associated or not to pain on percussion. The periapical status was examined using vertical percussion, palpation tests and the digital periapical radiographs. Symptomatic apical periodontitis was determined by sensitivity to percussion, and palpation tests, lack of response to thermal stimulus associated or not to radiograph findings suggestive of periapical lesion. To collect the signs and symptoms through clinical records were used two endodontist examiners.

\section{Treatment Procedures}

All RCT procedures were performed by undergraduate students who previously participated in an elective course of endodontic treatment in molar teeth. Treatment was performed in 2 to 4 visits depending on the case complexity and student performance, and the number of clinical sessions to conclude the endodontic treatment was recorded. Since molar teeth in young people are frequently partially erupted and additionally some teeth had caries or fracture extending subgengivally, periodontal surgery (crown lengthening) was performed before endodontic treatment when needed in order to allow tooth rubber dam isolation. All data regarding pre-operatory conditions were recorded (Table 1). Teeth were anesthetized using a local anesthetic solution containing 2\% lidocaine with 1:100,000 epinephrine (Alphacaine; DFL Indústria e Comércio Ltda, Rio de Janeiro, RJ, Brazil). After confirming adequate anesthesia, the tooth was isolated with a rubber dam, and endodontic treatment was undertaken. The pulp chamber access was prepared using spherical high-speed burs (KG Sorensen, Barueri, SP, Brazil). A glide path was established with manual K-files \#10, \#15 and \#20. The WL was determined after to find the initial file that fit the diameter of the apical constriction using an electronic apex locator (ProPex Pixi, Dentsply, Maillefer; Baillagues, Switzerland) and confirmed with digital periapical radiographs. The WL of each root canal was set at $1 \mathrm{~mm}$ shorter than apex. The canals were instrumented with nickel-titanium rotary files (Protaper 
Next, Dentsply, Maillefer) driven by the XSmart Plus ${ }^{\circledR}$ motor (Dentsply, Maillefer) in rotary motion. The rotary file X1 was moved in a slow and gentle in-and-out motion. After each three complete movements, the instrument was removed from the canal and its debris were cleaned off by sterile gauze. The same cinematic was maintained for $\mathrm{X} 2$ and $\mathrm{X} 3$ rotary files with no fracture of instrument in the mesial and buccal canals of molars. In addition, when necessary was used X4 file (40/0.06) in wider canals such as the distal and palatal. Each instrument was used to prepare 3 teeth. $3 \mathrm{ml}$ of $2.5 \%$ sodium hypochlorite (Asfer Quimica, São Bernardo do Campo, SP, Brazil) was used as irrigant in each root canal between the instruments during the procedure, with an approximate $9 \mathrm{ml}$ of total volume in each canal. The smear layer was removed by irrigating with $3 \mathrm{ml}$ of $17 \%$ ethylenediaminetetra acetic acid (EDTA, Asfer Quimica) for $1 \mathrm{~min}$, followed by final rinse with 5 $\mathrm{ml}$ of saline solution per canal. Irrigation procedure was performed with a $5 \mathrm{ml}$ Luer-Lok design syringe and separate syringes were used for each irrigation solution. NaviTip 30-G needles (Ultradent, South Jordan, UT) was used for all irrigation protocols and was placed at a distance of 2 $\mathrm{mm}$ close to the WL. For better dentinal walls cleaning, all

Table 1 . Main baseline characteristics of the teeth $(n=75)$

\begin{tabular}{|c|c|c|c|c|}
\hline Parameters & & Response & $\mathrm{n}$ & $\%$ \\
\hline \multirow{4}{*}{$\begin{array}{l}\text { Tooth } \\
\text { position }\end{array}$} & \multirow{2}{*}{ Maxilla } & First molar & 18 & 24.0 \\
\hline & & Second molar & 1 & 1.3 \\
\hline & \multirow{2}{*}{ Mandible } & First molar & 44 & 58.7 \\
\hline & & Second molar & 12 & 16.0 \\
\hline \multirow{4}{*}{$\begin{array}{l}\text { Pulpal } \\
\text { conditions }\end{array}$} & \multirow{2}{*}{ Pain } & No pain & 45 & 60.0 \\
\hline & & Spontaneous & 30 & 40.0 \\
\hline & \multirow{2}{*}{ Sensibility test } & Dull & 14 & 18.7 \\
\hline & & Negative & 61 & 81.3 \\
\hline \multirow{4}{*}{$\begin{array}{l}\text { Periodontal } \\
\text { conditions }\end{array}$} & Mobility & Yes & 7 & 9.3 \\
\hline & Horizontal percussion & Positive & 32 & 42.7 \\
\hline & Invasion of biologic space & Yes & 26 & 34.7 \\
\hline & Widening of PLS & Yes & 32 & 42.7 \\
\hline \multirow{4}{*}{$\begin{array}{l}\text { Periapical } \\
\text { conditions }\end{array}$} & Vertical percussion & Positive & 33 & 44.0 \\
\hline & Fistula & Yes & 6 & 8.0 \\
\hline & Apical palpation test & Positive & 6 & 8.0 \\
\hline & Periapical lesion & Yes & 53 & 70.7 \\
\hline \multirow{4}{*}{$\begin{array}{l}\text { Overall } \\
\text { baseline } \\
\text { score }\end{array}$} & Blocks of predictors & Range & Mean & SD \\
\hline & Pulpal & $0-3$ & 2.04 & 0.83 \\
\hline & Periodontal & $0-7$ & 1.87 & 1.67 \\
\hline & Periapical & $0-4$ & 1.76 & 0.79 \\
\hline
\end{tabular}

PLS: periodontal ligament space. irrigation protocols were manually activated by the syringe needle with corono-apical movements. Calcium hydroxide paste (UItracal XS, Ultradent, St Louis, MO, USA) was used as interappointment dressing in all treated teeth for 15 days. Checking for absence of pain, edema, fistula or odor was performed before obturation.

Before obturation of canals, the teeth were allocated into 2 groups based on the sealer used for the root canal obturation (RCO). Randomization was performed using software Sealed Envelope ${ }^{\circledR}$ (sealedenvelope.com-Ex, mouth House, London, UK) by the researcher who was not involved in the clinical protocol. A list with 60 numbers was prepared and divided in two blocks. Each sequence of numbers after randomization was individually placed in sealed and numbered envelopes. In the clinical session designated for obturation, after removing the intracanal medication and testing the master cone, immediately before filling, the researchers (C.C.G.M and C.J.S) took the box with the envelopes. The previously randomized envelope was then opened to find out which group the patient would be allocated. The patients were unaware of the assigned group throughout the duration of the study.

The root canals were then dried and filled with Sealer 26 - S26 (Dentsply Sirona, York, Pennsylvania, USA) or AH Plus - AHP (Dentsply Sirona) endodontic sealers using single cone technique. In cases where the canal was more oval, some accessory gutta-percha cones were also used for better sealing of the cervical and middle third. At the end of the endodontic therapy, all teeth were immediately sealed with resin-modified glass ionomer cement (Riva, SDI Limited, Bayswater, Victoria, Australia) until final restoration with composite resin. Occlusion was checked and a final digital radiography was performed.

\section{Variables}

Two independent, blind evaluators were for calibrated using 20 periapical radiographs of endodontically treated teeth not included in the study. The evaluators (S.A.C and C.P.R.) are endodontists with more than 8 years of clinical experience. The evaluation of these radiographs was repeated until intra- and inter-evaluator agreement was obtained with a Cohen's kappa coefficient higher than 0.80 . Radiographs were obtained initially, after endodontic procedure and after 1 and 2-year follow up (Fig. 1).

Outcomes (Dependent Variables): Two main clinical outcomes were assessed: apical repair and post-operatory pain. Time points for longitudinal assessment occurred 12 and 24 months after teeth restoration, performed by two highly qualified 
professional. Outcomes were measured at the tooth-level according to the following criteria: apical repair - absence of radiolucent image involving the apex of the restored tooth (yes/no response); post-operatory pain: absence of sensation of pain or discomfort elicited spontaneously or by stimulus as chewing (yes/no response).

Risk Factors (Independent Variables): Potential factors predisposing the occurrence of pain and fail in apical repair at the follow-up periods were assessed at baseline (before endodontic and restorative treatment) (Table 1). Factors were grouped as (1) pulpal, (2) periodontal, (3) periapical and procedural, and were classified as following:

-Pulpal conditions: dental pain (no pain and spontaneous pain), pulpal sensibility testing (dull/negative);

-Periodontal conditions: tooth mobility (no/yes), horizontal percussion testing (negative/positive), invasion of biologic periodontal space (no/yes), widening of periodontal ligament space (no/yes);

-Periapical conditions: dental fistula (no/yes), exacerbated sensitivity to vertical percussion (yes/no), response to the apical palpation test (negative/positive), presence of periapical lesion (no/yes) ;

-Procedural factors: surgical crown lengthening (no/yes), periodontal ostectomy (no/yes), rubber dam isolation (yes/no), number of appointments for treatment (count), changes of intracanal medication (count), type of endodontic filling material (AHP/S26), limit of obturation (satisfactory, overfilling, underfilling), time between obturation and definitive restoration.

\section{Data Analysis}

Data were tabulated at the restoration-level counts and percentages for each of the clinical variables assessed. Outcome measures at the two follow-up periods included the occurrence of periapical repair and pain in the restored teeth. To account for the violation of the assumption of independence of data, the risks for negative outcomes were modeled by mixed-model regression using generalized estimating equations (GEE), since data have a hierarchical structure due to the multiple observations within patient and the repeated measures in the time points of the longitudinal assessments. GEE models were specified as a Binomial distribution and Logit as the link function for a binary response. As some patients have more than one tooth restored, data was clustered as subject variables at the patient-level and restoration-level. In addition, as outcomes were assessed at different time points (timelevel), the within-subject variables were defined for each restoration for the repeated-measures data at the 1- and 2-year follow-ups.

For the GEE model construction, outcomes were labeled by setting the reference categories (code $=0$ ) as "positive radiographic repair" and "no pain". The likelihoods of the target categories (code=1) for each outcome were calculated by modeling the selected predictor variables at assessed at baseline (before restoration) building the models terms as main effects and their highest-level interactions. Preliminary analysis showed that, in many cases, a quasi-separation problem occurred where the outcome was almost perfectly separated by a function of the independent variables and time points. This problem was managed by combining blocks of predictors into three aggregated variables: pulpal, periodontal and periapical. The presence of each individual predictor $(\operatorname{code}=1)$ were summed to obtain a summative score of each clinical feature.

Hence, to construct the GEE model we first defined variable blocks representing characteristics of patients (age, gender), teeth (aggregated pulpal, periodontal and periapical features) and restorations (root-filling cement, type of restorative procedures). The selection of subsets of predictors was performed by entering simultaneous all independent variables of each block for significance hypothesis testing. A forced entry method was adopted and all predictors were first entered. After obtaining the best model fit, adjustments were made based on restorative dentistry
Figure 1. Radiographs of clinical cases (A-H): A and E: Initial conditions demonstration periapical lesions and severe coronal structure loss; B and F: radiography obtained after final endodontic procedure demonstrating adequate obturations; $\mathrm{C}$ and $\mathrm{G}$ : o after 1-year follow up demonstrating clear healing apical process; D and $\mathrm{H}$ : after 2-year follow up perfect healing apical process. 
protocols. GEE regression parameters estimates were expressed as regression coefficients (and 95\% confidence intervals), and significance of the model effects was tested using the Wald Chi-Square statistics. Random partitioning of the sample was used for validation of the final regression model. Statistical significance was set at $p<0.05$ and the IBM-SPSS 24.0 software was used for data analysis.

\section{Results}

The participant's flow diagram of the trial is presented in Figure 2. A total of 60 patients ( 75 teeth) were included in the initial sample. Twenty-seven (45\%) were female and $33(55 \%)$ male, age of the participants ranged from 9.6 to 17.8 years-old at the time of completion of endodontic treatment (mean $=14.2 ; \mathrm{SD}=2.6$ ). Most part of participants $(n=48)$ had only one tooth included in the sample, whilst 10 had two teeth and 2 had three teeth included in the study sample. Table 1 shows the main initial characteristics of the teeth at baseline, and Table 2 describes the main features of the endodontic and restorative procedures.

Outcomes were assessed at the 1- and 2-year followup. The time between endodontic root canal filling and definitive tooth restoration ranged from 0 to 109 days ( $m e a n=30 ; S D=28.1$ days). There were 3 teeth extracted

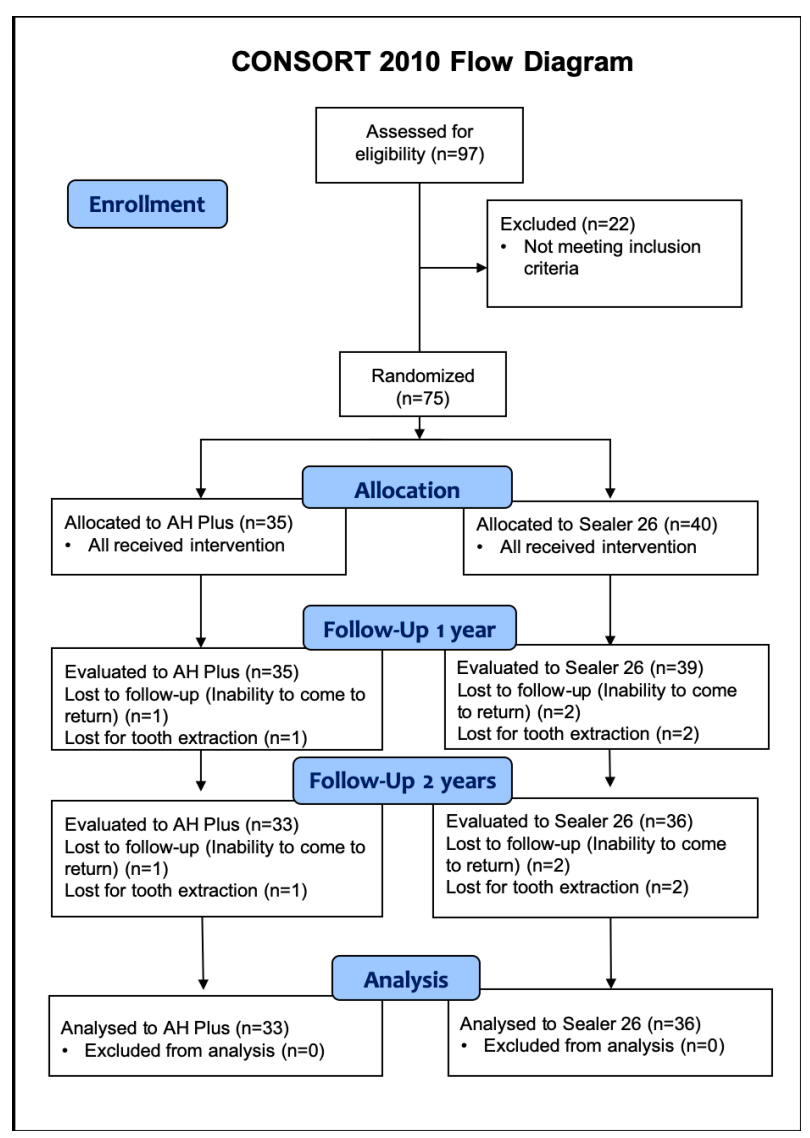

Figure 2. Patient flow diagram.

(in 3 patients) before the first follow-up and patients were excluded from analysis of the main outcomes. Other 4 teeth (in 4 patients) were excluded due to patient loss of follow-up and no outcome data available. Incomplete outcome data due to skipped visits or patient dropout were observed for 14 teeth - 3 in the first follow-up and 11 in the second follow-up, however, these teeth with censored data were not excluded from the longitudinal analysis, since the GEE procedure provides a weighted method for analyzing longitudinal data that have missing observations. Hence, the final sample size considered for analysis was 69 teeth (54 patients).

In the longitudinal outcome assessments, excluding the censored teeth, the incidence of teeth with apical repair was $90.5 \%(n=57)$ in the 1-year follow-up, and 89.3\% $(n=50)$ in the 2-year follow-up. Regarding dental pain,

Table 2. Frequency table of the main features of the endodontic and restorative treatments $(n=75)$

\begin{tabular}{lccc}
\hline Treatment / Procedure & & $\mathrm{n}$ & $\%$ \\
\hline Endodontic & AH Plus & 35 & 46.7 \\
$\begin{array}{l}\text { Type of endodontic } \\
\text { filling material }\end{array}$ & Sealer 26 & 40 & 53.3 \\
& & & \\
& One & 33 & 44.0 \\
Number of changes of & Two & 28 & 37.3 \\
intracanal medication & Three & 14 & 18.7 \\
& & & \\
& & & \\
& Two & 33 & 44.0 \\
Number of appointments & Three & 28 & 37.3 \\
& Four & 14 & 18.7 \\
& & & \\
& Satisfactory & 55 & 73.3 \\
Apical limit of root canal filling & Overfilling & 10 & 13.3 \\
& Underfilling & 10 & 13.3 \\
& Satisfactory & 60 & 80.0 \\
Quality of the restoration & Acceptable & 13 & 17.3 \\
& Unacceptable & 2 & 2.7
\end{tabular}

Restorative

\section{Rubber dam isolation \\ Surgical crown lengthening \\ Periodontal ostectomy}

\section{Time between endodontic}

filling and definitive restoration with composite resin

\begin{tabular}{ccc} 
Yes & 75 & 100 \\
Yes & 26 & 34.7 \\
Yes & 12 & 16.0 \\
& & \\
Up to 7 days & 26 & 34.7 \\
8-30 days & 19 & 25.3 \\
31-60 days & 15 & 20.0 \\
61-90 days & 12 & 16.0 \\
>90 days & 3 & 4.0 \\
\hline
\end{tabular}


the incidences of asymptomatic teeth were $96.8 \%(n=60)$ in the 1-year follow-up, and $90.0 \%(n=45)$ in the 2-year follow-up (Fig. 3). In summary, 6 teeth were diagnosed with failed apical repair and 5 teeth with dental pain at the end of the follow-up periods.

As the root-filling sealer was introduced as a random factor in the study design, it was maintained in the apical repair model even if its $p$-value was not significant. The same strategy was used for dental pain at baseline for prediction of dental pain as a clinical outcome.

Failed apical repair was associated with unsatisfactory pulpectomy $(p=0.003)$ and periapical $(p=0.007)$ conditions, as well as their interaction ( $p=0.016)$. Higher risk of failed apical repair was also found for AHP filling material, whilst not significant ( $p=0.093)$. The final multilevel regression model revealed that none of the independent variables was able to predict the occurrence of dental pain in the follow-up periods ( $p>0.05$ ).

Figure 4 illustrated the representative conditions of 2 -years radiographs demonstrating adequate root canal obturation with the most frequent intercurrences regarding obturation (satisfactory, overfilling, underfilling) and condensation (Fig. 4).
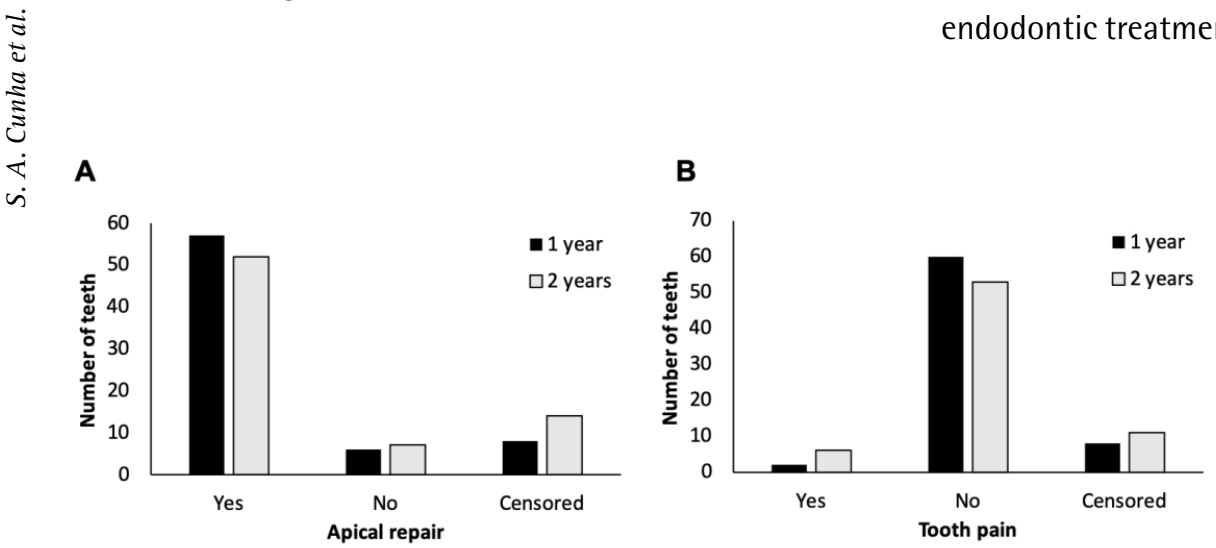

Figure 3. Incidence of apical repair (A) and dental pain (B) in the 1- and 2-year follow-up.

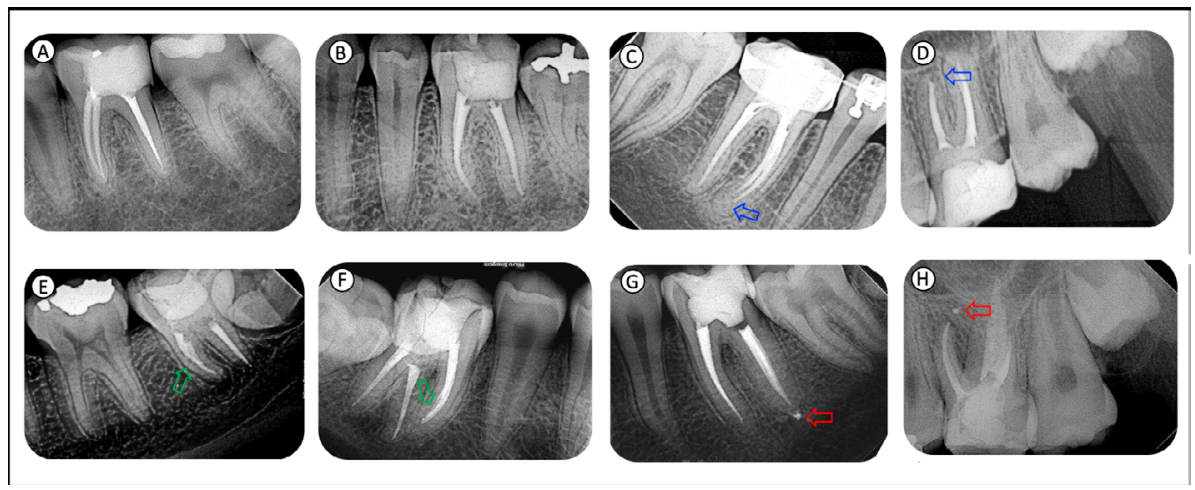

Figure 4. Radiographic quality parameters of root canal filings. A and B: Satisfactory obturations; C and D: underfilling examples - blue arrows; E: limited condensation green arrows; F-H: overfilling examples - red arrows.

\section{Discussion}

On the best author's knowledge, no comparable data are available in the current literature derived from clinical studies that specifically examined the clinical outcomes of endodontic treatment performed by undergraduate students in molar teeth of children and adolescents affected by caries and with extensive destruction of the dental crown. Previous studies reported the quality and outcomes of endodontic treatment in patients with similar age range (14), these were mainly conducted in traumatized anterior teeth or involving different teeth groups simultaneously (15). This topic has unique interest for endodontics due to the scarce data concern endodontic treatment of young molars teeth severally affected by caries, which involve patient less cooperative. The technical is more complicated related to the anatomic and eruption stage peculiarities in these teeth. Additionally, the importance of this study is due the fact that the procedures were conducted by undergraduate students.

The quality of endodontic treatment is overall poor except when executed by specialist endodontists $(6,14)$. However, in income countries, especially in public health service, there is a limited number of endodontists to perform endodontic treatment. It became necessary that clinicians and undergraduate students should be prepared to perform the endodontic treatment and direct restoration for maintaining the young permanent molar teeth affected by pulpitis, necrosis or apical periodontitis in children and adolescents. In clinical practice, the majority of RCT are performed by general dentists which turn extremely important to promote clinical training of undergraduates by making them competent for carrying out good quality endodontic treatments (8). Clinical studies have demonstrated the poor quality of endodontic treatment performed by undergraduate students especially when performing manual instrumentation (6). On the other hand, the use of rotatory $\mathrm{Ni}-\mathrm{Ti}$ instrumentation reduces the technical difficulties involved 
in the treatment of posterior teeth (8), minimizing accidents caused by the use of manual stainless-steel files such as apical transport (6). Becoming important to introduce the mechanical instrumentation the protocol using Ni-Ti files for undergraduate clinical training, all the teeth enrolled in this study were instrumented with Protaper Next ${ }^{\circledR}$ system, which has fast learning curve, good cyclic fatigue resistance (16). Additionally, fewer extrusion of apical debris has been observed with this protocol (17). Two years of clinical training significantly reduces the occurrence of inadequate obturation on treatments performed by dental students (7). Therefore, only undergraduate students on the $4^{\text {th }}$ and $5^{\text {th }}$ year that have performed more than three RCT previously and also have undergone advanced preclinical training for endodontic treatment in molars were selected to participate in this study. Despite preexisting studies evaluating the technical quality of endodontic treatments performed by undergraduate students $(7,8)$, a direct comparison with the present study is not possible. Several methodological variations are presented, and also none study has evaluated exclusively molar teeth severely structurally compromised by extensive caries. Additionally, the statistical analysis model used in current study allows evaluating baseline variables which could act as predictors for the risk of dental pain and failed apical repair, therefore influencing the outcome of the molars RCT.

The nature of the postoperative pain depends on the interaction between host immunological defense, infection and physical damage as extrusion of debris during RCT (18), over instrumentation, overextension of filling (11), chemical irrigants, and intracanal medicaments. Understand the post-operative pain predictors may help to manage this undesirable condition (19), and anticipate patients regarding possible pain occurrence after RCT (20). In the present study, none of the clinical parameters evaluated (pulpal, periodontal or periapical score) were able to identify predisposing factors for endodontic origin post-operative pain, which agree with previous research conducted in a Brazilian subpopulation (19). Such findings differ from previous studies in which postoperative pain have been associated with the periapical status (20), as presence of preexisting periapical lesion (18). Considering the multifactorial origin of pain, the contrast between the results of different studies might be related to the fact that the present study included non-standardization in the number of sessions in the treatment, ranging from two to four sessions, and the root canal instrumentation system used. Instrumentation techniques may possess a significant effect on post-operative pain (18). In the present study, only the rotary instrumentation with Protaper Next files was used, which result in a small extrusion of debris in the apical region (17) and could be related to the few reports of pain between the sessions.

Another factor of great relevance in the patient's perception of pain is the socioeconomic and cultural patterns (19). In the current analysis, all the patients had great social vulnerability, which often led the absence of attendance in the recall visit at the scheduled date, preventing a standardization of the periods for the measurement of pain. This difficulty in making the patient aware of the importance of attending to the recall appointments has been previously reported in randomized clinical trials (21). This fact, associated with the difficulty in obtaining accurate data regarding pain from children and adolescents after one week, prevented the application of a numeric scale of pain. In this way data were collected only regarding the presence or absence of pain on the day that the patient attended the recall appointment.

The long-term success of endodontic treatment has also been evaluated by the emergence or persistence of apical periodontitis (21), named in the present study as apical repair. Success of primary RCT is often related to the absence of periapical radiolucency, the length of obturation within $2 \mathrm{~mm}$ to the apex and satisfactory coronal seal $(22,23)$. Although these parameters have been evaluated in our study, they were not used as independent variables for statistical analysis, since the focus of the evaluation was to estimate the risk of failure in periapical repair as a function of pulpal, periapical, periodontal scores, and type of endodontic sealer used for obturation.

Regarding the apical limit of the obturation, 73.3\% were considered satisfactory, that is, up to $2 \mathrm{~mm}$ below the apex, which is a result relatively close to the $81 \%$ found in a previous study enrolling endodontic treatment of permanent teeth in children (14). The present findings cannot be directly compared to the previous studies, since most of them focused on the adult population (10,21-23). Scarce studies involving children and adolescents are not restricted to molars (15), or have just assessed the parameter quality of the obturation (22). The periapical status of rootfilled teeth in children and adolescents was evaluated in previous study, however just 21\% of treated teeth were molars, which presented optimal or good radiographic periapical status in $61 \%$ of the treated teeth (15). However, it was a retrospective study, all treatments were performed by trained professionals already. The high percentages of adequate obturation and healing rates reported in current research, may be related to the fact that the treatments were performed in an academic environment under strict operating control by a professor and also to adequate coronary sealing with definitive restorations (21-23).

In fact, there is no consensus regarding the optimal length of obturation $(10,24)$. Some studies based on radiographic analyses recommend RCO ending from 1 to 2 
$\mathrm{mm}$ short of the radiographic apex $(10,21,23)$. Other study considers RCO coincident with the tip of apex appropriate in teeth without apical periodontitis (9). A concern of the present study was the fact that young molar teeth have a frequent wider foramen. This anatomical characteristic makes difficult to maintain the filling material restrict into the root canal, which could lead to extravasation of the endodontic sealer, influencing on the periapical repair. However, in this study this fact was not observed occurred since only $13.3 \%$ of the cases presented overfilling. In the present study, two epoxy resinous sealers were used, one of them containing calcium hydroxide (S26), and the other one, AHP, which is considered the gold standard. Previous clinical study compared extruded eugenol-based sealers with AHP and Apetix ${ }^{\circledR}(9)$, which has composition similar to that of S26. Teeth obturated with AHP or S26 had similar risk of failure in the apical repair, probably due to the small percentage of the teeth with overfilling. Previous studies comparing the effects of different sealers on the outcome of endodontic treatment demonstrating low or lack of interference on the healing along the time, even in cases with previous apical periodontitis $(9,11)$. Another intercurrence related to the unintentional extravasation to evaluated, for both sealers used.

Surprisingly, the periodontal score was not considered as a risk factor for the existence of failure in the periapical repair. This fact represents great clinical relevance, since teeth with great coronary destruction may require surgery to increase the clinical crow. The use of osteotomy to allow absolute isolation and restore the biological distance, which occurred in 34.7\% of the teeth of this study. The influence of periapical status on the estimates risk of apical repair failure has been extensively reported, although these studies have evaluated different teeth and patients ages $(21,25)$. Preexisting periapical conditions have been addressed to have more dominant role than the pulpal condition for periapical healing (21). The influence of pulp status on periapical repair is controversial, which was found in our study.

Another aspect cannot be overlooked in the present study is the low cooperation of patients to receive endodontic and restorative procedures. The lack of children cooperation as anxiety and hysterical behavior have been related to less satisfactory outcomes in endodontic treatments (14). Although these parameters had not been evaluated in this study, it is likely that specific cases of failure could also be related to poor patient cooperation. Other limiting factors such as the number of sections required by the undergraduate students, the necessity of surgical increase in clinical crown, difficulty in rubber dam isolation should be a concern during the treatment of this type of patients.

Despite the limitations of the present study, high success rates were observed. It is important to emphasize the great socioeconomic impact of this study, since it allows the endodontic treatment and maintenance of permanent molars in young and children in a condition of vulnerability. Moreover, the present findings show that it is possible to train undergraduates to perform endodontic treatments of high complexity with a satisfactory quality standard, and that the type of sealer used is not relevant since the filling is contained within the root canal.

\section{Resumo}

A rápida progressão das lesões de cárie nos dentes molares permanentes de pacientes jovens, frequentemente resulta no tratamento endodôntico. Este ensaio clinico randomizado cego avaliou o efeito de dois cimentos endodônticos (Sealer 26 e AH Plus) na incidência de dor e reparo apical após tratamento endodôntico de dentes molares jovens e identificar fatores associados aos desfechos do tratamento. 0 tratamento endodôntico foi realizado por estudantes de graduação em dentes molares permanentes $(n=69)$ de pacientes jovens $(n=54)$ na Clínica de Extensão Endodôntica e Restauradora da Universidade Federal de Uberlândia, Brasil. Protaper Next foi usado e os dois cimentos foram distribuidos aleatoriamente nas amostras, as quais foram restauradas com resina composta direta. Dois desfechos clínicos primários - reparo apical e dor pós-operatória foram avaliados após 12 e 24 meses por operadores de forma cega. Análise longitudinal dos dados incluiu a descrição das taxas de incidência e modelo de regressão misto usando Equações de Estimativa Generalizadas (GEE). As incidências (\%) do reparo apical e dos dentes assintomáticos foram respectivamente 90,5/89,3 e 96,8/90,0 nos periodos de 1 e 2 anos de acompanhamento. Ausência de reparo apical foi associada com pulpectomia insatisfatória $(p=0,003)$ e condições periapicais $(p=0,007)$, bem como sua interação $(p=0,016)$. Nenhuma dessas variáveis independentes foi capaz de prever a ocorrência de dor nos periodos de acompanhamento. 0 tratamento endodôntico mostrou resultados satisfatórios após 2 anos. 0 prognóstico do reparo apical depende das condições iniciais. Nenhum efeito do cimento endodôntico foi observado. 0 tratamento endodôntico de molares jovens associado com restaurações em resina composta realizado por estudantes de graduação tem um papel relevante na redução do risco de perda do dente permanente.

\section{References}

1. Dean AA, Bark JE, Sherriff A, Macpherson LM, Cairns A. Use of the 'Hall technique' for management of carious primary molars among Scottish general dental practitioners. Eur Arch Paediatr Dent 2011;12:159-162.

2. Santos PS, Martins-Júnior PA, Paiva SM, Klein D, Torres FM, Giacomin $A$, et al. Prevalence of self-reported dental pain and associated factors among eight- to ten-year-old Brazilian schoolchildren. PLoS One 2019;14:e0214990.

3. Maran S, Shashikiran ND, Ahirwar P, Maran P, Raj Kannojiya P, Niranjan B. Prevalence of Dental Caries and Traumatic Dental Injuries among 6- to 12-year-old Children in Bhopal City, India. Int J Clin Pediatr Dent 2017;10:172-176.

4. Al-Madi EM, AI Saleh SA, Bukhary SM, Al-Ghofaily MM. Endodontic and Restorative Treatment Patterns of Pulpally Involved Immature Permanent Posterior Teeth. Int J Dent 2018;2018:2178535.

5. Deepti A, Shifa S, Muthu MS, Rathna Prabhu V. Apical closure of immature molar roots: a rare case report. Int J Clin Pediatr Dent 2008;1:54-57.

6. Ribeiro DM, Réus JC, Felippe WT, Pacheco-Pereira C, Dutra KL, Santos 
$J N$, et al. Technical quality of root canal treatment performed by undergraduate students using hand instrumentation: a meta-analysis. Int Endod J 2018;51:269-283.

7. Alsulaimani RS, Al-Manei KK, A Alsubait $S$, AlAqeely RS, A M Al-Shehri S, M Al-Madi E. Effects of clinical training and case difficulty on the radiographic quality of root canal fillings performed by dental students in Saudi Arabia. Iran Endod J 2015;10:268-273.

8. Donnelly A, Coffey D, Duncan HF. A re-audit of the technical quality of undergraduate root canal treatment after the introduction of new technology and teaching practices. Int Endod J 2017;50:941-950.

9. Ricucci D, Rôças IN, Alves FR, Loghin S, Siqueira JF Jr. Apically Extruded Sealers: Fate and Influence on Treatment Outcome. J Endod 2016;42:243-249.

10. de Sousa Gomide Guimarães MRF, Samuel RO, Guimarães G, Nalin EKP, Bernardo RT, Dezan-Júnior $E_{1}$ et al. Evaluation of the relationship between obturation length and presence of apical periodontitis by CBCT: an observational cross-sectional study. Clin Oral Investig 2019;23:2055-2060.

11. Shashirekha G, Jena A, Pattanaik $S$, Rath J. Assessment of pain and dissolution of apically extruded sealers and their effect on the periradicular tissues. J Conserv Dent 2018;21:546-550.

12. Schulz KF, Altman DG, Moher D. CONSORT Group. CONSORT 2010 Statement: updated guidelines for reporting parallel group randomised trials. Trials 2010;11:32.

13. Shahravan A, Haghdoost AA, Rad M, Hashemipoor M, Sharifi M. Sample size calculation of clinical trials published in two leading endodontic journals. Iran Endod J 2014;9:56-60.

14. Clarke $P$, Jones $A D$, Jarad F, Albadri S. Technical outcome of root canal treatment on permanent teeth in children: a retrospective study. Eur Arch Paediatr Dent 2015;16:409-415.

15. Jordal K, Valen A, Örstavik D. Periapical status of root-filled teeth in Norwegian children and adolescents. Acta Odontol Scand 2014;72:801805.

16. Topçuoglu HS, Topçuoglu G, Akti A, Düzgün S. In vitro comparison of cyclic fatigue resistance of ProTaper Next, HyFlex CM, OneShape, and ProTaper Universal Instruments in a canal with a double curvature. J
Endod 2016:42:969-971.

17. Sen OG, Bilgin B, Koçak S, Saçlam BC, Koçak MM. Evaluation of apically extruded debris using continuous rotation, reciprocation, or adaptive motion. Braz Dent J 2018;29:245-248.

18. Shokraneh A, Ajami M, Farhadi N, Hosseini M, Rohani B. Postoperative endodontic pain of three different instrumentation techniques in asymptomatic necrotic mandibular molars with periapical lesion: a prospective, randomized, double-blind clinical trial. Clin Oral Investig 2017;21:413-418.

19. Gomes MS, Böttcher DE, Scarparo RK, Morgental RD, Waltrick SBG, Ghisi AC, et al. Predicting pre- and postoperative pain of endodontic origin in a southern Brazilian subpopulation: an electronic database study. Int Endod J 2017;50:729-739.

20. Law AS, Nixdorf DR, Aguirre AM, Reams GJ, Tortomasi AJ, Manne BD, et al. Predicting severe pain after root canal therapy in the National Dental PBRN. J Dent Res 2015;94:37S-43S.

21. $\mathrm{Ng} \mathrm{YL}$, Mann $\mathrm{V}$, Gulabivala $\mathrm{K}$. A prospective study of the factors affecting outcomes of nonsurgical root canal treatment: part 1 : periapical health. Int Endod J 2011;44:583-609.

22. Asgary S, Shadman B, Ghalamkarpour Z, Shahravan A, Ghoddusi J, Bagherpour A, et al. Periapical Status and Quality of Root canal Fillings and Coronal Restorations in Iranian Population. Iran Endod J 2010;5:74-82.

23. Kielbassa AM, Frank W, Madaus T. Radiologic assessment of quality of root canal fillings and periapical status in an Austrian subpopulation - An observational study. PLoS One 2017;12:e0176724.

24. Mello FW, Miguel AFP, Ribeiro DM, Pasternak B Jr, Porporatti AL, FloresMir $C$, et al. The influence of apical extent of root canal obturation on endodontic therapy outcome: a systematic review. Clin Oral Investig 2019;23:2005-2019.

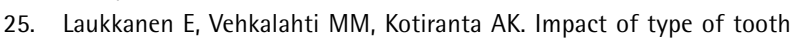
on outcome of non-surgical root canal treatment. Clin Oral Investig 2019;23:4011-4018.

Received January 29, 2020 Accepted July 1, 2020 